Received: 23/07/2018

Revision: 02/10/2018

Accepted: 07/10/2018

OnlineFirst: 10/12/2018

\title{
The Impact of Musical Mnemonic on Vocabulary Recalling of Iranian Young Learners
}

\author{
Zahra Nikkhah Bahrami \\ Department of English Language Teaching, Islamic Azad University, Zanjan \\ BranchZanjan, Iran, zahra.nikkhah.bahrami1978@gmail.com
}

\section{Siros Izadpanah}

Corresponding author, Department of English Language Teaching, Islamic Azad University, Zanjan BranchZanjan, Iran, cyrosizadpanah@yahoo.com \& sirosizadpanah@iauz.ac.ir

\section{Houman Bijani}

Department of English Language Teaching, Islamic Azad University, Zanjan BranchZanjan, Iran, houman.bijani@gmail.com

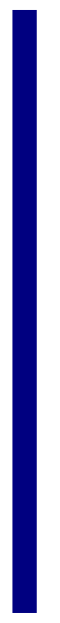

\begin{abstract}
Vocabulary as an undeniable part of language learning is a main component in communication which requires to be taught in innovative ways. The purpose of this study was to examine the effect of musical mnemonic on vocabulary recalling, and long-term retention of words by young learners. The design of study was experimental. Sixty teenagers from Shokoh Language Institute in small town of Khorramdare, Iran participated in the study. To conduct the study, participants were divided into experimental and control groups. A list of 14 words were harmonized to melody of mentioned song and recorded in a professional studio. Validity of the words were examined by Lawsh CVR (Content Validity Ratio) and CVI (Content Validity Index). The results from Independent T-Tests indicated that experimental group outscored control group. Regarding research questions, it was found that musical mnemonic improves vocabulary recalling of experimental group in comparison to control group. In addition, results related to research questions showed that musical mnemonic help learners better understand words in new contexts. The findings imply that musical mnemonic can improve memory, and comprehension by practicing, and using melodic and rhythmic information.
\end{abstract}

Keywords: musical mnemonic, vocabulary remembering, vocabulary comprehension, language learning, young learners

Citation: Bahrami, Z. N., Izadpanah, S. \& Bijani, H. (2019). The Impact of Musical Mnemonic on Vocabulary Recalling of Iranian Young Learners. International Journal of Instruction, 12(1), 977-994. https://doi.org/10.29333/iji.2019.12163a 


\section{INTRODUCTION}

Learning a new language requires learning different skills including speaking, listening, writing, and reading. It is very important to know that acquiring all of these skills requires learning grammar, vocabulary, and pronunciation (Cimermanová, 2018). A language learner cannot communicate effectively without knowing enough vocabulary. Vocabulary is essential for listening and reading comprehension. Writing is formed by using appropriate vocabularies (Fasih, Izadpanah, \& Shahnavaz, 2018). Successful vocabulary choice even results in good use of grammar. Therefore, the importance of learning and memorizing vocabulary is an undeniable part of language learning. Wilkins (1972, as cited in Dehjalali \& Izadpanah, 2017) stated that showing meaning without grammar is partially possible but without vocabulary is impossible. Vocabulary has been recognized as meaning carrier. There is a mutual relationship between lexical knowledge and communication. The more lexical knowledge a learner gains, the more competent s/he will be in communication and vice versa (Alqahtani, 2015; Bouchaib, Ahmadou, \& Abdelkader, 2018). Speaking fluently is one of the problems that language learners face in speaking. Because of little vocabulary knowledge, not recalling vocabularies, and using the same words and expressions repeatedly, learners feel despair and interrupt communication. To overcome lack of vocabulary knowledge and memorize vocabularies, teachers play a key role to help learners. Using appropriate teaching methods and techniques by teachers assists learners to acquire vocabularies easier and faster and recall them while speaking.

Despite the fact that music has been used in language learning and teaching process for many years, it is basic for educators and researchers to locate an appropriate strategy to aid learning process and minimize language learning obstacles, especially in memorizing vocabularies and using them in interactions. In spite of importance of vocabulary memorizing and interaction in language learning process, few studies have examined interaction effect of music on vocabulary learning. Additionally, memorizing and remembering a wide range of vocabularies assist learners to better perform in listening, comprehension, writing, and reading situations. It is suggested to use creative ways of teaching like using music and songs in order to make vocabulary learning more enjoyable and help learners improve their vocabulary remembering. Therefore, it is essential to investigate the effect of music on comprehension of new vocabularies which is received the least attention among other language components. Another motivation for conducting this study is theoretically-based. Based on Krashan`s affictive filter hypothesis (1982), the weaker is the affective filter, the more productive is learning and the more positive is attitude. Using different types of music relieves learners anxiety and stress and makes a classroom a relaxing place for better learning. In addition, Gardener`s (1993) theory of multiple intelligences referred to musical intelligence as an ability in every human being. In addition, he stated that music has useful effect in learning language since it improves learning process in learners with strong right hemisphere (Madani, Mahmoodi, 2017). Another point is that in Iran, which is a foreign language context, most learners do not develop a balanced interlanguage regarding different dimensions of production, and most of them have problems in fluency and difficulty performing tasks in real-life tasks. Learners usually complains about forgetting 
vocabularies or not remembering words to express their meaning. In Iran, there is not enough opportunity to be exposed to English language due to the fact that English is not used outside the classroom; therefore, it is up to teacher, syllabus designers, material developers to provide tasks and creative techniques to fill this gap. The aim of this study is to investigate the impact of musical mnemonics on learners vocabulary remembering in their learning process.

\section{Research Questions}

The following research questions led the course of the present study:

1) What is the effect of musical mnemonics instruction on word recalling by young EFL learners?

2) What is the effect of musical mnemonics instruction on comprehension of new words?

\section{Literature Review}

English as an international language plays a key role in communication around the world. Every day, people from different countries use English to communicate with people of other countries, different cultures and nationalities. Learning and teaching English is widespread in different schools, institutes, and language centers in every part of the world. Most of science, knowledge, and research sources are published in English. So, it is necessary to find a way for teaching and learning English effectively. Although there are various methods, techniques, and strategies to teach and learn English, it has been seen that learners complain about communication problems. Generally, language learning and capability of speaking English requires to acquire some skills and components. Vocabulary is one of important components of language which makes communication possible. Learning, memorizing, and remembering vocabularies are essential because using appropriate vocabulary assist individuals express themselves clearly. So, finding a technique, method, or strategy which aids learners memorize vocabularies make communication easier and learning more enjoyable for them. One of challenges that EFL learners face in process of learning particularly while trying to communicate in English is recalling words. According to O'Hógain (2012), learning all language skills and components are important for language proficiency; however, lack of vocabulary knowledge impedes communication. It is necessary for researchers and language teachers to find a proper technique by which learners can expand range of their vocabulary. In addition, using innovative ways which create joyful and enjoyable atmosphere in classroom can help learners improve their vocabulary knowledge.

\section{IMPORTANCE OF MUSIC}

Generally, music is defined as an art of mind in which sounds are organized into time and tune. Music carries words, tunes, rhythms, feelings, cultural values and literature. Jules Combarieu, a French musicologist, stated that "Music is the art of thinking with sounds." (cited in Dent, 1913; as cited in Nnanyelugo, \& Ukwueze, 2017, p.142). Music is a common language in the world that does not need translation. There are various 
types of music styles and musical instruments regarding cultural and national values around the world. Everyone talks about music. The young listen to their favorite type of music style. The old enjoy listening to their favorite music. People from different classes of society know music. People use music to show their happiness, soothe their pains, and relax. Today music is present everywhere. You can hear music in shopping centers, stores, cafés, restaurants, gyms etc. It is played in movies, TV shows, videos games to create more excitement and passion. A large number of people spend their time listening to music while working, studying, relaxing, exercising daily. Furthermore, new technologies have made listening to music easier than past in every place and situation (Rentfrow, 2012). People like to attend in concerts and spend money to buy new albums of their favorite musicians and singers. Overall, music plays a crucial role in daily life of individuals. A large number of research studies have been conducted to investigate the effect of music on different aspects of life such as health, sport, education, languages, psychology etc. (Brown, 2014; Fasih, Izadpanah, \& Shahnavaz, 2018; Ferrari, 2012; Hallam, 2010; Karageorghis \& Priest, 2012; Rentfrow, 2012; Salecedo,2010).

\section{MNEMONICS}

In general, mnemonics are defined as memory devices and recall aid which help learners remember information. The word "mnemonic" derived from Greek meaning memory which is a special memory enhancement (Rosdiana, 2009). According to Amiryousefi and Ketabi (2011), origin of mnemonic comes from Greek word "Mnemosyne" which refers to the goddess of memory in ancient Greece. It is stated that early mnemonics was used about 500 B.C. Amiryousefi and Ketabi (2011, as cited in Solso, 1995) defined mnemonics as an improvement technique or memory enhancement device which aid information processing including encoding, storage, and recall in memory. Additionally, they believed that mnemonics are useful in a way that they speed learning by incorporating new information into cognitive and intellectual units. Bakken and Simpson (2011) defined mnemonic as an instruction method which makes recall of information easier. In addition, they stated that mnemonics connect new information with old familiar information using pictures, words, letters, and combination of them

\section{Iranian and International Studies on Musical Mnemonic on Vocabulary Recalling}

Recently, research studies have focused on effect of music and song on different language skills and components, especially vocabulary. As it was mentioned, vocabulary is important part of language without which communication will be difficult. Different studies have investigated the effect of song and music on EFL and ESL learners' vocabulary knowledge.

In a research study, Madani and Mahmoodi Nasrabadi (2017) investigated the effect of songs on vocabulary retention of preschool EFL learners. Participants of the study were 103 six years old young learners. To homogenize the participants, a pretest in a form of interview was conducted. Treatment was conducted in an experimental group $(n=62)$ and a control group $(n=51)$. Songs were presented in experimental group during 20 sessions while teaching vocabularies which were extracted from songs. Control group received no song. In order to measure the effect of songs on vocabulary retention of 
learners, researchers conducted a posttest in the form of interview like pretest. Then, a delayed post-test was conducted to measure learners' vocabulary retention. Results from SPSS showed that experimental group outperformed control group in vocabulary retention. The experimental data of Madani and Mahmoodi Nasrabadi (2017) are controversial and there is not enough information about pretest and posttest process. Researchers did not mention to criteria and process of interviews as pretest and posttest and how learners were scored. In addition, research question related to gender differences was not answered in the study.

In another study, Shakerian, Rezaei, Murnani, and Moeinmanesh (2016) examined the effect of pop songs on 60 Iranian advanced English learners' vocabulary recall. Participants were 30 male and 30 female English learners aged from 20 to 32 . To homogenize participants, Oxford Quick Placement was conducted and participants were divided into experimental and control group. After 20 sessions of treatment teaching vocabularies with pop songs, a posttest was administered to measure vocabulary gain of learners. In order to measure delayed effect of songs, the same posttest was readministered a month later. According to the findings, experimental group outperformed control group. In addition, it was found that male learners scored higher than female learners. This study investigated advanced adult learners' vocabulary recall. Researchers have not made it clear that how vocabularies for teaching sessions have been chosen from songs and there are not enough details regarding treatment sessions. Since results of the mentioned study were for advanced adult learners, it cannot answer the research questions of the present study.

In a comparative study, Heidari and Araghi (2015) investigated the effect of songs and pictures on vocabulary gain of EFL learners. They conducted the study on 68 male learners at the age range of 7-14. A vocabulary test was administered to measure vocabulary knowledge of learners as a pretest. In treatments sessions, one group received lessons using songs and another groups received lessons using pictures. Then a posttest was administered to both experimental groups. Results showed that there was no significant difference between pretest and posttest of experimental group received songs. However, results from picture group showed a significant difference between scores of participants in pretest and posttest. Comparison of scores in posttest of song and picture group confirmed that participants of picture group outperformed participants of song group. In this study, participants were just males; therefore, results cannot generalize to females. Additionally, materials and instruments used in experimental groups were not mentioned in the study.

Abdolmanafi-Rokni and Ataee (2014) conducted a study to examine the effect of background music on 7 to 11 years old elementary EFL learners' vocabulary retention and recall. Lessons were taught in 20 sessions which in experimental group was along background music and in control group there was no music. Finally, a vocabulary posttest was presented to both groups. Findings showed that experimental group outscored control group in vocabulary recall and retention. In this study, generalization of findings is controversial, since participants are just female learners. Additionally, background music was chosen by the researcher and learners taste of music was not 
considered in this study. Furthermore, it was not mentioned that what type of vocabularies was selected for teaching to learners.

In a study, Kusnierek (2016) studied the role of music and songs on vocabulary memorization of English learners in a primary school in Poland. Two groups of experimental $(n=14)$ and control $(n=14)$ including beginner English learners aged from 11-12 were in the study. Learners were in their fifth grade. First, a questionnaire was distributed to explore attitude of learners toward music and songs. In a pretest, learners were asked to write as many verbs as they remember in two different groups. Then, teacher asked learners to guess a song which has one of the verbs written by learners. Learners could guess the same song played by teacher. After listening to songs, learners wrote as many verbs as they remembered. Next, a fill in the blank task was distributed among learners which contained lyrics of song. Fill in the blank task was checked and correct answers were written on the board by the teacher. After the treatment and song lessons, students were given some homework to memorize words at home and asked to fill in an evaluation questionnaire. Results from comparison of pretest and posttest showed that learners of experimental group outperformed in writing of verbs and their translation. Results of the questionnaire study showed that students enjoyed music and song lessons. This study explored the effect of music on EFL learners' vocabulary memorization. The experimental data of this study are controversial, since instruments used are questionnaires which are not validated and their reliability are not measured.

In a study in ESL context Malaysia, Razak and Yunus (2016) investigated the impact of songs on primary school students' word gain. During treatment sessions, researcher taught action words to students using traditional method in six sessions and next six sessions were spent to teach action words using action songs. At the end of treatment, a group interview was conducted. This study had one experimental group in which students exposed to both traditional and action songs method. There was not enough detail on the action words used in both methods. In other words, researcher did not clarify whether the same action words were taught learners in both methods or not. Although researcher mentioned that learners' exposure to English was little because of socio-economic status of families, this study was conducted in ESL context. Therefore, findings of the study cannot generalize to EFL context in which learners have zero exposure to communicative language. Additionally, this study investigated the students word comprehension and attitude toward action song and cannot answer the questions of present study.

Mudawi (2015) conducted a study on the role of songs and rhymes and their effect on vocabulary knowledge of elementary students in Saudi Arabia. Participants, 15 females and 15 males, were in sixth grade of elementary school. A pretest was conducted to homogenize participants. Females were appointed to experimental group and males were appointed to control group. Experimental group received lessons through songs and rhymes while control group received traditional method of teaching. Researcher taught 50 nursery songs and rhymes during

In another EFL context, effectiveness of songs was examined on vocabulary gain of young learners in second grade of elementary school in Indonesia (Burhayani, 2013). 
Participants were students of second grade, 25 in experimental group and 25 in control group. First, a pretest was given to evaluate background vocabulary knowledge of students. Treatment was conducted six times using songs in experimental group. Then, a posttest was conducted to evaluate vocabulary improvement of students. Posttest scores confirmed that songs can improve vocabulary mastery of students. In this study, design of research was not clarified. It was not mentioned to vocabulary types, materials used for songs, and test items. Furthermore, it cannot answer the questions of the present study because learners were in second year of their primary school in both control and experimental group which is not the same range of the present study.

Abidin, Pour-Mohammadi, Singh, Azman, and Souriyavongsa (2011) conducted a study in order to investigate the effect of using songs on vocabulary gain of EFL learners in a secondary school in Malaysia. Experimental group were exposed to songs in YouTube and other mentioned activities. After six sessions, a vocabulary post-test was administered. In this study, students and their performance were observed and documented during treatment sessions. Results from the vocabulary tests showed that both experimental and control groups hadimprovement in vocabulary proficiency level but experimental group showed higher difference in scores of pre-test and post-test. Findings of observation checklists and journal writing showed that students had positive feeling of using songs in learning process. This study cannot answer questions of the present study, since research questions of study just have investigated and compared vocabulary competence of students.

Studies reviewed in this section were conducted to investigate effect of songs and music on vocabulary gain of language learners in different contexts. Most of the above mentioned studies examined the effect of songs on vocabulary gain of young learners in elementary levels and some studies focused on adult learners. In addition, some of studies did not clarify the materials used in their studies. Overall, above mentioned studies cannot answer the research questions of the present study regarding sample age range and the materials used. Another important reason is that the present study has used music as a mnemonic device i.e. participants of the study were taught vocabularies of their book using a familiar song of "Let It Go" by Indina Menzel.

\section{METHOD}

\section{Participants}

Population of the study were 90 teenagers learning English as a Foreign Language in Shokoh language institute in small town of Khorramdare, Iran. While the data were collected, learners were being taught Hey There 3 A book. Learners attended their English classes three days in a week. According to placement of the institute, participants were in intermediate level. However, present study has administered a Sample Quick Placement Test to select homogeneous groups from the population.

In order to select the final participants of the study, a Sample Quick Placement Test was taken. The test included 50 items including grammar and vocabulary sections. After test administration, 60 learners were selected based on their test scores, one standard 
deviation below and above the mean (+/-1 SD), who were considered to be in the same proficiency level. Participants were both male and female aged from 14 to 19.

Selected participants were assigned into two groups, non-musical group $(\mathrm{n}=30)$ and musical group $(\mathrm{n}=30)$ using simple random sampling.

\section{Instruments}

Three instruments were used in the present study. First, a Sample Quick Placement Test, as a renowned standardized language proficiency test, was the first instrument utilized at the beginning of the study to check the homogeneity of English proficiency level of learners, especially on grammar and vocabulary section and choose final sample of the study. However, just the vocabulary and grammar section was used, since in this study the researcher's focus was on the vocabulary ability of the learners. The test included 50 items, 1- 40 grammar questions and 41-50 vocabulary questions. In this pre-test, learners were given 60 minutes to complete the test. Next, learners were placed in different levels using a benchmark which includes five levels: Beginner (0-15), Elementary (16-24), Pre-intermediate (25-32), Intermediate (33-39), Upper Intermediate (40-45), and Advanced (46-50) (see Appendix A).

Next instrument was a list of words which learners were supposed to learn and remember in the study. The researcher selected a list of 14 random vocabularies from the book Hey There $3 \mathrm{~A}$ which was taught in the language institute which participants were learning English. In fact, all of the new words from lessons were 30. In order to select the target words of the study, a board of experts reviewed the words. It should be mentioned that board of experts included both professional English teachers and musicians. Since this study uses musical mnemonic, it is essential that some expert musicians confirm the harmony of the selected words by melody and rhythm of the used music. After review of the words by 10 experts, 14 words which have no relation to one another in content and sentence structure were selected. In word selection, content validity was evaluated using Lawsh CVR (Content Validity Ratio) and CVI (Content Validity Index). Lawsh formula is as following:

$\mathrm{CVR}=\frac{(\mathrm{Ne}-\mathrm{N} \div 2)}{\mathrm{N} \div 2}$

According to the Lawsh CVR, an item should gain CVR of higher than 0.42 in order to be validated.

Then CVI of the words were calculated using Waltz and Bausell (1981). CVI formula is as following:

$\mathrm{CVI}=\frac{\text { Number } \text { of experts } \text { who scored item } 3 \text { or } 4}{\text { Total number of experts }}$

It should be mentioned that the acceptable index of CVI equals 0.79 and if there is an item with CVI lower than 0.79 , the item should be removed.

In other words, a panel of experts determined whether the selected words are "necessary" to be included in the study based on a 4-point Likert scale. Experts 
indicated their opinions on each word using 1(It is not necessary), 2 (It is rather necessary), 3 (It is necessary), and 4 (It is completely necessary).

After word selection, list of words was recorded in a song format to the familiar melody of "Let It Go" by Indina Menzel in musical mnemonics context. The participants were given a printed hardcopy of the word list to use during each session. Familiar melody plays a helpful role in learning new information and provides a link between melody and text (Pindale, 2013). In addition, familiar song of "Let It Go" by Indina Menzel was harmonized the melody and syntax of the words in the list. It is worth noting that recording of the musical mnemonic of word list was conducted in a professional studio under supervision of skillful musicians. Vocalist sang the word list to the melody of "Let It Go" for musical mnemonic condition. It should be mentioned that the vocalist was familiar with English and was taught how to pronounce the words correctly. For the nonmusical group, vocalist just stated each word of the same list at one word per second.

Table 1

Word List

\begin{tabular}{ll}
\hline Words & \\
\hline 1. Goal & 8. Scientific \\
2. Score & 9. Genius \\
3. Tackle & 10. Discount \\
4. Cheer & 11 . Borrow \\
5. Dressy & 12. Beat \\
6. Lazy & 13. Gloves \\
7. Moody & 14. Communicate \\
\hline
\end{tabular}

Third instrument was a post-test collected by the researcher to measure vocabulary comprehension and remembering by participants in both control group and experimental group. It should be mentioned that comprehension test included fill in the blank questions collected from standard test of Hey There 3 Tests. In order to measure reliability of final test, test-retest reliability was used. The post-test included two different sections. In the first section, participants were asked to complete list of vocabularies they remembered. First section of post-test was conducted in four trials each in four different sessions. Participants were asked to write as many words as they remembered in the list provided. Second section included multiple-choice questions which assessed vocabulary comprehension of participants. This section of the test was conducted after four trials sessions.

\section{Procedure}

Initially, participants were selected and homogenized using a pre-test to check their proficiency level. To this end, a Sample Quick Placement Test was conducted to $90 \mathrm{EFL}$ learners studying in a language institute. Their proficiency level was rated based on the benchmark of Sample Quick Placement Test, which includes five levels: Beginner (015), Elementary (16-24), Pre-intermediate (25-32), Intermediate (33-39), Upper Intermediate (40-45), and Advanced (46-50). 
Then scores were submitted to SPSS to measure inter-rater reliability via Cronbach's alpha. Additionally, normality of the data was examined via the one-sample Kolmogorov-Smirnov (K-S) test and Shapiro-Wilk test. Results of the proficiency test were presented in chapter 4 . Next, participants were assigned into two groups: nonmusical group which was considered as a control group $(n=30)$ and musical group which was considered as an experimental group $(n=30)$.

\section{Design of the Study}

In the present study, a pre-test (a Sample Quick Placement Test) was used to homogenize the participants and participants were randomly divided into two groups: control and experimental group. Randomization is advantageous since it shows that any difference in post-test should be result of experimental variable. Design of the study was experimental in which participants were randomly assigned into experimental and control groups. In this study, music had been used as an independent variable and dependent variables were vocabulary remembering, of vocabulary, and vocabulary comprehension. Scores of the participants in post-test was compared. The dependent variables were examined independent of each other.

\section{Data Collection}

Data were collected scoring post-test in which participants answered to one, two, and three trials of filling in word list in succession, and fourth trial 10 days after the third trial. Moreover, vocabulary comprehension scores were collected from answers to 14 multiple-choice questions. Total score of the post-test was 28. Scoring was effective in that helped the researcher investigate the effect of musical mnemonics on vocabulary remembering, , and vocabulary comprehension of EFL learners. Also, remembering trials enabled the researcher to examine the effect of musical mnemonics on musical group in comparison to non-musical group.

\section{Data Analysis}

Data were analyzed using the Statistical Packages for Social Sciences (SPSS) Version 21. In order to compare participants scores in control and experimental groups, scores of both pre-test and post-test were analyzed by Independent T-Test to consider equality of means. According to the results of the Independent T-Test, it can be concluded whether musical mnemonics have any effect on vocabulary remembering, long-term vocabulary remembering, and vocabulary comprehension of participants. Furthermore, the difference of results was examined on the above mentioned factors by gender.

\section{FINDINGS}

\section{Results of Pre-test}

In order to have homogeneous groups, a pre-test (a Sample Quick Placement Test) was administered to select homogeneous participants. Population of the study was 90 teenagers learning English as a Foreign Language in Shokoh language institute in small town of Khorramdare, Iran. The test included 50 items including grammar and vocabulary sections. After test administration, 60 learners were selected based on their 
test scores, one standard deviation below and above the mean (+/-1 SD), who were considered to be in the same proficiency level. The result of the test is presented below.

Table 2

Descriptive Statistics of Participants Scores on Pre-Test

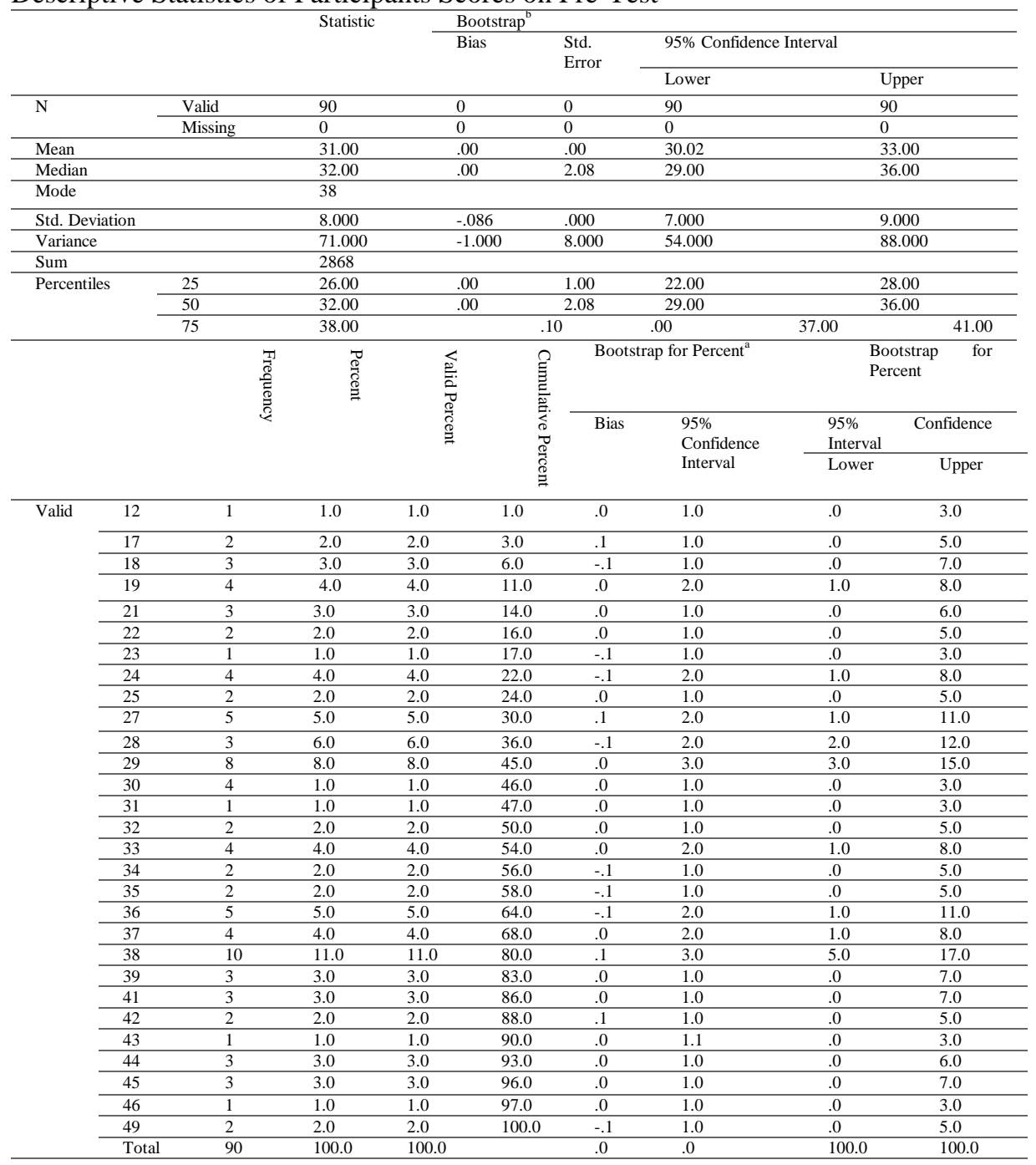

\section{Results of Reliability}

In the present study, a post-test including 14 multiple-choice questions was designed to measure vocabulary comprehension of learners in musical and non-musical groups. Questions of test were selected from standard Mixed-Ability worksheets of Hey There 
3A. However, a statistical test was used to measure the reliability of new target test. To measure reliability, Cronbach's Alpha was used to show the reliability of the post-test (Table 3).

Table 3

Estimation of Reliability of Post-test

\begin{tabular}{ll}
\hline Cronbach's Alpha & N of Items \\
\hline 0.794 & 14 \\
\hline
\end{tabular}

As it can be seen in the table, the reliability value is 0.794 which is relatively high and in satisfactory level (above 0.7).

\section{Data Analysis of First Research Question}

The first research question was about the effect of musical mnemonics instruction on word recalling by young learners. To this end, participants were asked to fill in blank papers as many vocabularies as they remembered in both control and experimental groups. Then scores of participants were entered in SPSS, measured and compared using two independent samples t-test. In the following, first, descriptive statistics of participants' performance in terms of word recall are presented in table 4 .

Table 4

Descriptive Statistics of Participants' Performance in Terms of Word Recall

\begin{tabular}{llllll}
\hline & music & $\mathrm{N}$ & Mean & Std. Deviation & Std. Error Mean \\
\hline \multirow{2}{*}{11} & 1 Musical & 30 & 12.00 & 1.000 & .000 \\
\cline { 2 - 6 } & 2 Non-musical & 30 & 10.00 & 2.000 & .000 \\
\hline
\end{tabular}

As it can be seen in table 4.4, the mean and standard deviation of musical group are 12 and 1 respectively while the mean and standard deviation of non-musical group are 10 and 2 respectively. The mentioned statistics show the effect of musical mnemonic on word recall of learners. However, two independent samples t-test was run to statistically examine the significance of difference. Table 5 shows the results of the test.

Table 5

The Independent Samples T-Test for Word Recall

\begin{tabular}{|c|c|c|c|c|c|c|}
\hline & & \multicolumn{3}{|c|}{ Levene's Test for Equality of Variances } & \multicolumn{2}{|c|}{ t-test for Equality of Means } \\
\hline & & & $\mathrm{F}$ & Sig. & $\mathrm{t}$ & Df \\
\hline \multirow{2}{*}{ f1 } & Equal variances assumed & & 15.000 & .000 & 3.037 & 58 \\
\hline & Equal variances not assumed & & & & 3.037 & 43.000 \\
\hline \multicolumn{7}{|c|}{ t-test for Equality of Means } \\
\hline & & $\begin{array}{l}\text { Sig. (2- } \\
\text { tailed) }\end{array}$ & $\begin{array}{l}\text { Mean } \\
\text { Difference }\end{array}$ & $\begin{array}{l}\text { Std. Error } \\
\text { Difference }\end{array}$ & $\begin{array}{l}95 \% \\
\text { Confidence } \\
\text { Interval of the } \\
\text { Difference }\end{array}$ & $\begin{array}{l}95 \% \\
\text { Confidence } \\
\text { Interval of the } \\
\text { Difference }\end{array}$ \\
\hline \multirow{3}{*}{ fl } & & & & & Lower & Upper \\
\hline & Equal variances assumed & .004 & 1.000 & .000 & .000 & 2.000 \\
\hline & Equal variances not assumed & .004 & 1.000 & .000 & .000 & 2.000 \\
\hline
\end{tabular}

As the table indicates, the variance of groups is not equal. Furthermore, it can be seen that significance difference $(.000)$ is lower than $0.05(\mathrm{t}(43)=3.037, \mathrm{p}<0.05)$, i.e., the 
difference between means of musical and non-musical group is statistically significant. Therefore, the first null hypothesis is rejected. It can be stated that instruction of musical mnemonics has effect on word recall of language learners.

\section{Data Analysis of Second Research Question}

The second research question was constructed to examine the possible effect of musical mnemonics on vocabulary comprehension of learners. To test the hypothesis, a test including 14 multiple choice questions was administered between musical (experimental group) and non-musical (control group) groups. First, descriptive statistics was presented in table 6, then; two independent samples t-test was run to show the statistical effect of independent variable.

Table 6

Descriptive Statistics of Participants' Performance in Terms of Word comprehension

\begin{tabular}{llllll}
\hline & Music & $\mathrm{N}$ & Mean & Std. Deviation & Std. Error Mean \\
\hline \multirow{2}{*}{$\mathrm{f} 2$} & $1 \mathrm{Musical}$ & 30 & 11.00 & 1.000 & .000 \\
\cline { 2 - 6 } & 2 Non-musical & 30 & 10.00 & 2.000 & .000 \\
\hline
\end{tabular}

As seen in Table 6, the mean and standard deviation of the data obtained from the musical group were 11 and 1 respectively. The mean and standard deviation of the data obtained from the non-musical group were 10 and 2 respectively. So the effect of musical mnemonics instruction on vocabulary comprehension of learners can be clearly seen. In order to see whether this difference was statistically significant or not, two independent samples t-test was run. The results are reported in Table 7.

Table 7

The Independent Samples T-Test for Vocabulary comprehension

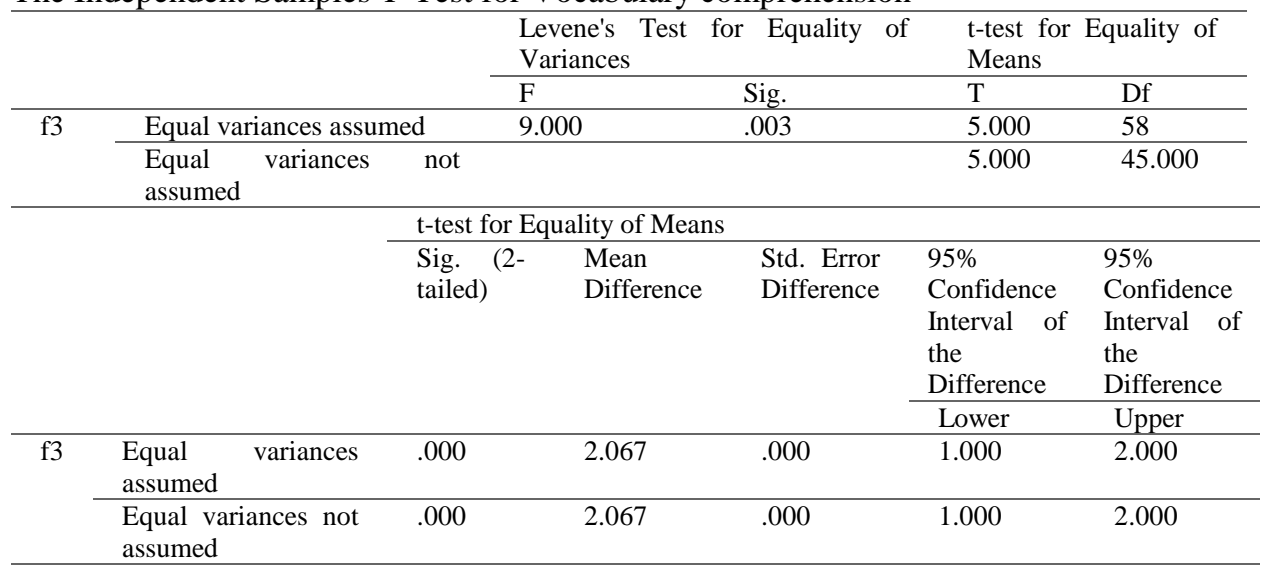

Table 7 indicates that the variance of the groups is not equal; therefore, the second line must be reported, i.e., $\mathrm{t}(45)=5, \mathrm{p}<0.05$. Since the level of significance is less than .05 , it can be stated that the difference between the means of the musical and nonmusical groups in terms of vocabulary comprehension was statistically significant. Hence, based on the results, the second null hypothesis was nullified. 


\section{DISCUSSION}

The first research question examined whether musical mnemonics had an effect on vocabulary remembering of EFL learners. Results of the present study indicated that participants of musical group outperformed non-musical group. It means that musical group could remember more words than non-musical group. Therefore, there was an effect of musical mnemonics on vocabulary remembering of EFL learners.

This finding corresponds with previous studies in which English learners could remember greater words following musical mnemonics sessions than non-musical learners (Abdolmanafi-Rokni \& Ataee, 2014; Burhayani, 2013; Kusnierek, 2016; Madani \& Mahmoodi Nasrabadi, 2017; Mudawi, 2015; Razak \& Yunus, 2016; Shakerian et al., 2016; Salcedo, 2010). Abdolmanafi-Rokni and Ataee (2014) claimed that background music help learners pay attention more to instructions and develop vocabulary retention in those who were exposed to music. Alipour et al. (2012) also claimed that using songs as a useful way can help vocabulary improvement and develop recall and retention among higher level students. According to Kusnierek (2016), using songs for teaching vocabularies is helpful in a way that it sticks the words into long-term memory and improve retention of words. Madani and Mahmoodi Nasrabadi (2017) showed that songs assist learners to remember new vocabularies easier and improve their vocabulary learning. Mudawi (2015) believed that songs and nursery rhymes are useful tools to help children absorb information like core words in learning language. According to Razak and Yunus (2016), action songs are effective ways to improve action vocabulary remembering among primary school children. Shakerian et al. (2016) declared that pop songs instruction can help adult language learners better remember words and improve retention.

In this study, it was seen that using musical mnemonics help language learners remember more new vocabularies in comparison to those who have not been taught through musical mnemonic instruction. It can be implied that music as a mnemonic device includes characteristics such as melody and rhythm which influence memory improvement through repetition and rehearsal of musical words and recalling new information.

The second research question examined whether use of musical mnemonics influence new word comprehension. Findings of the present study showed that using musical mnemonics improve comprehension of new words among EFL learners. According to the findings, participants of musical group outperformed participants of non-musical group. It appears that using musical mnemonics help learners better understand meaning of the words in new contexts. The findings of the present study are in line with some previous studies (Abidin et al., 2011; Burhayani, 2013; Razak \& Yunus, 2016; Shakerian et al., 2016) regarding effect of musical mnemonics on comprehension of new words.

Abidin et al. (2011) concluded that use of songs while teaching improve vocabulary competence of upper secondary school students. Burhayani (2013) believed that using songs is an effective way that helps learners understand difficult words easily and 
improve their word knowledge. Razak and Yunus (2016) argued that using action songs assist low-proficiency children to better comprehend action words. They also claimed that action songs improve learning new words.

Regarding comprehension of new words, it was found that learners taught through musical mnemonic could answer more correctly to multiple-choice questions than those who did not receive musical mnemonic instruction. Understanding and using words in new contexts is one of major challenges which language learners face in learning process. Integration of innovative instructional ways like musical mnemonic in teaching vocabularies helps learners learn new words faster and easier.

\section{IMPLICATIONS}

This study provides evidence of the effect of music as a mnemonic device on vocabulary learning and teaching. First, this study provides evidence that music can facilitate vocabulary remembering. Second, this study represents additional evidence that music as a mnemonic device can improve vocabulary comprehension of language learners. Third, the study indicated that music is an effective way to memorize vocabularies longer. Theoretically, findings of the present study were in line with Audiolingual Method which used music to decrease boredom in language classrooms, Suggestopedia model which utilized classical music to provide relaxing environment for mind and improve reception of inputs, Communicative Language Teaching (CLT) and Task Based Language Learning (TBLT) which demanded for innovative educational and pedagogical approaches and materials in language classrooms (Engh, 2013). Furthermore, it should be stated that the mentioned teaching methods have roots in psychology, structural linguistic, affective-humanistic approach, and communicative approach.

Regarding the practical implications, this study represents evidence of improvement in memory of learners through musical mnemonic technique by practicing and rehearsal. Language learners need to memorize and retain a large number of vocabularies, information, grammatical structures, phrases, and expressions. Therefore, results of this study indicates that an individual can learn and retain information by practicing.

In addition, findings of the study reveal that music as a mnemonic device can be an effective and enjoyable way to practice and memorize information. Music includes characteristics like melody and rhythm which make learning and memorizing easier and enjoyable. Repetition and rehearsal of melodic and rhythmic information cause information to be categorized into groups. In addition, music provides a link between new information and familiar melody of music.

\section{Suggestions for Further Research}

Future research should continue to examine the effect of musical mnemonic on different aspects and components of language including grammar, pronunciation, speaking, listening, reading, and writing skills. Future studies should include larger samples to decrease variance level between groups in order to achieve significant results. 
In addition, future studies can compare and contrast different types of familiar music styles to better learn about learners tastes and also pedagogical impact of different music styles. It is also suggested that future research conduct musical mnemonic studies using more trial session to see effect of musical mnemonic on longer period of time in order to gain in-depth findings.

Furthermore, it is recommended that future studies to examine the effect of musical mnemonic on vocabulary learning and other skills of population with deficits like deaf, blind, Autism disorders, Hyperactive children, and memory deficits. Therefore, researchers should begin to investigate the effect of musical mnemonic on vocabulary remembering and other language skills in clinical population.

Finally, future studies should take into account different types of mnemonics and examine the effect of mnemonic techniques such as music, key words, pictures, storytelling, and others on vocabulary remembering, and different language skills.

\section{CONCLUSION}

The purpose of this study was to investigate the effect of musical mnemonics on vocabulary remembering, new vocabulary comprehension, and long-term retention of vocabularies by young EFL learners. Using familiar music as a mnemonic device in some trials showed that musical mnemonic assist learners to improve their memory by rehearsal trials, therefore; learners could remember more new vocabularies. Findings of the study also suggests that music as a mnemonic device can improve vocabulary comprehension of new words and help language learners learn new words easier and faster. In addition, it can be concluded that musical mnemonic is effective way to memorize information for a long period of time. These findings support the effect of musical mnemonic as a learning tool in some reasons.

Musical mnemonic because of its elements such as melody, rhythm make learning new information not only enjoyable for the learners but also create clues for better retrieval and memorizing of new information. In other words, music makes learning easier by improving encoding, storing, and remembering capability through repetition and grouping information into organized categories. Moreover, music simplifies learning since it creates a link between music and taught information. Finally, it is suggested that music makes learning enjoyable and motivates learners to learn new information like word lists and lyrics faster and easier. Further works need to be done to investigate that whether music as a mnemonic tool can be used in language classrooms in all learning levels.

\section{REFERENCES}

Abdolmanafi-Rokni, S. J., \& Ataee, A. J. (2014). The effect of background music on vocabulary recall and retention of children learning English as a foreign language. International Journal of Basic Sciences \& Applied Research, 3(8), 491-495.

Abidin, M. J., Pour-Mohammadi, M., Singh, K. K., Azman, R., \& Souriyavongsa, T. (2011). The effectiveness of using songs in YouTube to improve vocabulary 
competence among upper secondary school studies. Theory and Practice in Language Studies, 1(11), 1488-1496. doi:10.4304/tpls.1.11.1488-1496

Alipour, M., Gorjian, B., \& Zafari, I. (2012). The effects of songs on EFL learners' vocabulary recall and retention: The case of gender. Advances in Digital Multimedia (ADMM), 1(3), 140-143.

Alqahtani, M. (2015). The importance of vocabulary in language learning and how to be taught. International Journal of Teaching and Education,3(3), 21-34. DOI: 10.20472/TE.2015.3.3.002

Amiryousefi, M., \& Ketabi, S. (2011). Mnemonic Instruction: A Way to Boost Vocabulary Learning and Recall. Journal of Language Teaching \& Research, 2(1), 178182. DOI:10.4304/jltr.2.1.178-182

Bakken, J. P., \& Simpson, C. G. (2011). Mnemonic strategies: Success for the youngadult learner. The Journal of Human Resource and Adult Learning, 7(2), 79-85.

Bouchaib, Ahmadou, \& Abdelkader, (2018). High school students' attributions of success in english language learning. International Journal of Instruction, 11, 89-102.

Brown, L. L. (2014). The benefits of music education. PBS Parents. PBS. org. nd Web.

Burhayani, N. (2013). The effectiveness of teaching vocabulary through songs to the second years students of ikatan keluarga kesejahteraan tentara (ikkt) elementary school west jakarta. 2nd International Seminar on Quality and Affordable Education (ISQAE 2013).

Cimermanová, I. (2018). The effect of learning styles on academic achievement in different forms of teaching. International Journal of Instruction, 11(3), 219-232.

Dehjalali, M. R., \& Izadpanah, S. (2017). The study of vocabulary awareness effect on intermediate language learners' depth of vocabulary knowledge in genuine persian texts. International Journal of English Linguistics, 7(1), 185-200. DOI:10.5539/ijel.v7n1p185

Fasih, P., Izadpanah, S., \& Shahnavaz, A. (2018). The effect of mnemonic vocabulary instruction on reading comprehension of students. International Journal of Applied Linguistics and English Literature, 7(3), 49-59. DOI: 10.7575/aiac.ijalel.v.7n.3p.49

Ferrari, E. (2012). Music as a lifelong learning opportunity. Procedia-Social and Behavioral Sciences, 46, 805-810. DOI: 10.1016/j.sbspro.2012.05.203

Hallam, S. (2010). The power of music: Its impact on the intellectual, social and personal development of children and young people. International Journal of Music Education, 28(3), 269-289. DOI: 10.1177/0255761410370658

Heidari, A., \& Araghi, S. M. (2015). A comparative study of the effects of songs and pictures on Iranian EFL learners' 12 vocabulary acquisition. Journal of Applied Linguistics and Language Research, 2(7), 24-35. 
Karageorghis, C. I., \& Priest, D. L. (2012). Music in the exercise domain: a review and synthesis (Part II). International review of sport and exercise psychology, 5(1), 67-84. DOI: 10.1080/1750984X.2011.631027\%20

Kusnierek, A. (2016). The role of music and songs in teaching English vocabulary to students. World Scientific News, 43(1), 1-55.

Madani, D, \& Mahmoodi Nasrabadi, M. (2017). The effect of songs on vocabulary retention of preschool young English language learners. International Journal of Research Studies in Language Learning, 6(3), 63-72.

Mudawi, G. H. H. (2015). Using rhymes and songs for teaching core vocabulary to elementary school students. ELT Voices, 5(1), 51-62.

Nnanyelugo, E. C., \& Ukwueze, C. C. (2017). What is music? A definitional enquiry into the concept and meaning of music as art, science and technology. International Journal of Communication, 20(1), 139-143.

O’Hagan, B. (2012). Teaching and learning vocabulary: Putting The Four Strands to the test.

Razak, N. A. N. A., \& Yunus, M. M. (2016). Using action songs in teaching action words to young esl learners. International Journal of Language Education and Applied Linguistics, 4, 15-24.

Rentfrow, P. J. (2012). The role of music in everyday life: Current directions in the social psychology of music. Social and personality psychology compass, 6(5), 402-416. DOI: 10.1111/j.1751-9004.2012.00434.X

Rosdiana, I. (2009). The Effectiveness of mnemonic devices in vocabulary learning process: a pre experimental study at the fifth grade of SDN Babakan I.

Salcedo, C. S. (2010). The effects of songs in the foreign language classroom on text recall, delayed text recall and involuntary mental rehearsal. Journal of college teaching and learning, 7(6), 19-30.

Shakerian, P., Rezaei, O., Murnani, Z. T., \& Moeinmanesh, H. (2016). Investigating the Role of Pop Songs on Vocabulary Recall, Attitude and Retention of Iranian EFL Learners: The Case of Gender. Advances in Language and Literary Studies, 7(2), 121128. DOI: $10.7575 /$ aiac.alls.v.7n.2p.121 